\title{
Terminal hemimelia of the lower extremity: absent lateral ray and a normal fibula
}

\author{
Goo Hyun Baek • Jae Kwang Kim • Moon Sang Chung • \\ Sang Ki Lee
}

Received: 18 September 2006 / Accepted: 20 October 2006 / Published online: 15 February 2007

(C) Springer-Verlag 2007

\begin{abstract}
Congenital lateral ray deficiency is considered to be a manifestation of fibular hemimelia. However, we have noted patients with absent lateral ray but stable knee and ankle joints, and named this condition terminal hemimelia of the lower extremity. This study was undertaken to further define this group of patients and to compare these patients with fibular hemimelia patients. Four boys and one girl of mean age six years two months were in the terminal hemimelic group and four boys and three girls of mean age eight years seven months in the fibular hemimelic group at the final evaluation. Clinical features commonly observed in the fibular hemimelia such as knee valgus, knee instability, tibial bowing, ball and socket ankle, ankle instability, tarsal coalition, leg length inequality were compared between both groups. Terminal hemimelia of the lower extremity was the same as fibular hemimelia in clinical features below the ankle joint. However, terminal hemimela was found to be milder than fibular hemimelia in terms of limb shortening. The clinical features above the ankle joint were different between both groups. Knees and ankles were stable, and gait disturbance were rarely noticed in patients with terminal hemimelia of the lower extremity.
\end{abstract}

G. H. Baek $(\bowtie)$

Department of Orthopedic Surgery, College of Medicine,

Seoul National University,

28 Yongon-dong, Chongno-gu,

Seoul 110-744, Korea

e-mail: ghbaek@snu.ac.kr

\section{J. K. Kim}

Department of Orthopedic Surgery, College of Medicine,

Ewha Woman's University,

Seoul, Korea

M. S. Chung $\cdot$ S. K. Lee

Department of Orthopedic Surgery, College of Medicine,

Seoul National University,

Seoul, Korea
Résumé Le déficit congénital du rayon externe doit être considéré comme une manifestation de l'ectromélie longitudinale externe. Cependant, nous avons noté chez certains patients présentant une absence du rayon latéral un genou et une cheville stables. Nous l'avons appelé dans ces conditions hémimélie terminale de l'extrémité inférieure. Cette étude a pour but de définir ce groupe de patients et de comparer ces patients avec l'ectromélie longitudinale externe classique. 4 garçons et une fille, d'âge moyen 6 ans et deux mois présentant une hémimélie terminale et 4 garçons et trois filles, d'âge moyen de 8 ans et sept mois présentant une ectromélie longitudinale externe ont été étudiés. Etude clinique : les éléments cliniques habituels dans l'ectromélie longitudinale externe tel que l'instabilité, le valgus du genou, la courbure tibiale, la cheville en dôme avec instabilité et la synostose du tarse postérieur ainsi que l'inégalité de longueur ont été comparés dans les deux groupes, l'hémimélie terminale de l'extrémité inférieure est identique à l'ectromélie longitudinale externe en ce qui concerne la cheville, cependant, l'hémimélie terminale entraîne un raccourcissement du membre moins important que l'ectromélie longitudinale externe. Les éléments cliniques, au niveau de la cheville, sont différents dans les deux groupes. Le genou et la cheville sont stables. Il y a peu de trouble de la marche habituellement chez ces patients.

\section{Introduction}

Fibular hemimelia is the most common type of limb deficiency and is not an isolated malformation but rather a part of a spectrum of dysplasia of the entire lower limb. This syndrome is often associated with other anomalies of the lower limb, such as limb shortening, absent lateral rays 
Table 1 Summary of cases

\begin{tabular}{|c|c|c|c|c|c|c|c|c|c|}
\hline & Age* & Sex & $\begin{array}{l}\text { Number } \\
\text { of Ray }\end{array}$ & $\begin{array}{l}\text { FCR } \\
(\%)\end{array}$ & $\begin{array}{l}\text { Ankle } \\
\text { Morphology }\end{array}$ & $\begin{array}{l}\text { Tarsal } \\
\text { Coalition }\end{array}$ & $\begin{array}{l}\text { LLD } \\
(\mathrm{mm})\end{array}$ & $\begin{array}{l}\text { Expected } \\
\text { LLD }(\mathrm{mm})\end{array}$ & Operation \\
\hline TH 1 & $7+10$ & M & 3 & 84 & B\&S & $\mathrm{T}-\mathrm{Ca}$ & 19 & 28.5 & \\
\hline TH 2 & $8+5$ & M & 3 & 82 & $\mathrm{~B} \& \mathrm{~S}$ & & 19 & 27.0 & \\
\hline TH 3 & $5+4$ & M & 4 & 86 & $\mathrm{~B} \& \mathrm{~S}$ & & 18 & 31.9 & \\
\hline TH 4 & $4+2$ & $\mathrm{~F}$ & 4 & 85 & $B \& S$ & $\mathrm{Ca}-\mathrm{Cu}$ & 14 & 25.2 & \\
\hline TH 5 & $7+5$ & M & 4 & 84 & $B \& S$ & T-Ca, T-N & 13 & 19.8 & \\
\hline FH 1 & $6+2$ & $\mathrm{~F}$ & 3 & 74 & $\mathrm{~B} \& \mathrm{~S}$ & & 23 & 34.3 & \\
\hline FH 2 & $4+4$ & $\mathrm{~F}$ & 4 & 73 & $\mathrm{~B} \& \mathrm{~S}$ & T-Ca, $\mathrm{Ca}-\mathrm{Cu}$ & 33 & 58.4 & \\
\hline FH 3 & $3+3$ & M & 4 & 68 & $\mathrm{~B} \& \mathrm{~S}$ & & 26 & 56.4 & \\
\hline FH 4 & $12+3$ & $\mathrm{~F}$ & 4 & 78 & $B \& S$ & $\mathrm{Ca}-\mathrm{Cu}$ & 34 & 36.0 & Epiphysiodesis \\
\hline FH 5 & $10+11$ & M & 4 & 71 & $B \& S$ & T-Ca, T-N & 51 & 63.2 & $\begin{array}{l}\text { Lengthening \& Valgus } \\
\text { deformity correction }\end{array}$ \\
\hline FH 6 & $11+0$ & M & 4 & 73 & $\mathrm{~B} \& \mathrm{~S}$ & T-Ca, $\mathrm{Ca}-\mathrm{Cu}$ & 45 & 55.8 & $\begin{array}{l}\text { Lengthening \& Valgus } \\
\text { deformity correction }\end{array}$ \\
\hline FH 7 & $12+0$ & M & 4 & 63 & $B \& S$ & $\mathrm{~T}-\mathrm{Ca}$ & 31 & 36.6 & $\begin{array}{l}\text { Lengthening \& Medial } \\
\text { femoral epiphysis stapling }\end{array}$ \\
\hline
\end{tabular}

FCR; femoral condylar ratio, LLD; leg length discrepancy, TH; terminal hemimelia, FH; fibular hemimelia, M; male, F; female, B\&S; ball \& socket, T-Ca; talocalcaneal, $\mathrm{Ca}-\mathrm{Cu}$; calcaneocuboidal, T-N; talonavicular

*Years + months

of the foot, ball and socket ankle joint, tarsal coalition, hypoplasia of the lateral femoral condyle with knee valgus.

Several classifications have been proposed to describe fibular hemimelia. The most widely used is that of Achterman and Kalamachi [1]. This system divides fibular hemimelia into type IA, IB, II according to the severity of fibular hypoplasia and all require some element of fibular hypoplasia. Recently, Searle CP et al. [9] proposed type 0 fibular hemimelia which has features of fibular hemimelia syndrome except for radiographically normal fibulae.

Congenital lateral ray deficiency is generally considered to be a manifestation of fibular hemimelia. However, we have noted patients with an absent lateral ray and a normal fibula and named this condition terminal hemimelia of the lower extremity. These patients have some of the typical features of fibular hemimelia, but differ in other respects. This study was undertaken to further define terminal hemimelia of the lower extremity and to compare patients with this condition with mild fibular hypoplasia patients.

\section{Patients and methods}

We reviewed the medical records and radiographs of patients with congenital lateral ray deficiency over 15-year period (Sept 1988-Oct 2003). Patients with complete or partial absence of the fibula were excluded as were patients with follow-ups of less than two years (Table 1).

Fibular hypoplasia was evaluated using lower leg radiographs, which included knee and ankle joints. Fibulae have been generally considered to show no evidence of hypoplasia if the proximal fibular epiphysis is at the level of the proximal tibial physis and the distal fibular physis is no higher than the tibial plafond [4]. However, these criteria are subjective and interobserver variance is likely in the differentiation mildly hypoplastic and normal fibulae. Thus, we measured the length of fibulae and tibiae from the proximal to the distal physis in normal and defective sides, and length discrepancies of tibiae in normal and defective sides were compared with those of fibulae. In the fibular hemimelic group, the length discrepancies of fibulae were larger than that of tibiae. On the other hand, the length discrepancies of fibulae were the same as those of tibiae in the terminal hemimelic group (Fig. 1).

The terminal hemimelic group contained four boys and one girl of mean age six years two months (range, four years two months-eight years five months) at final evaluation. The right side was affected in three limb segments, the left in two. Of these five feet, two had a three-ray foot and three a four-ray foot. There were four boys and three girls of mean age eight years seven months (range, three years three months-twelve years three months) in the fibular hemimelic group at final evaluation. Final evaluations were conducted before surgical treatment if a patient was to undergo the surgical treatment. The right side was affected in four limb segments and the left in three. Of these seven feet, one had a three-ray foot and six four-ray foot. All patients in our series had unilateral involvement, and none had identified syndromes.

Leg lengths were measured on plain radiographic scanograms. Limb length discrepancy at maturity was predicted 
Fig. 1 Terminal hemimelia of the lower extremity patient. a. Radiograpy of foot with two lateral rays absence. b. Proximal fibular epiphysis is at the level of the proximal tibial physis and the distal fibular physis is no higher than the tibial plafond in terminal hemimelia. The length discrepancies of fibulae between both limbs were same as those of tibiae
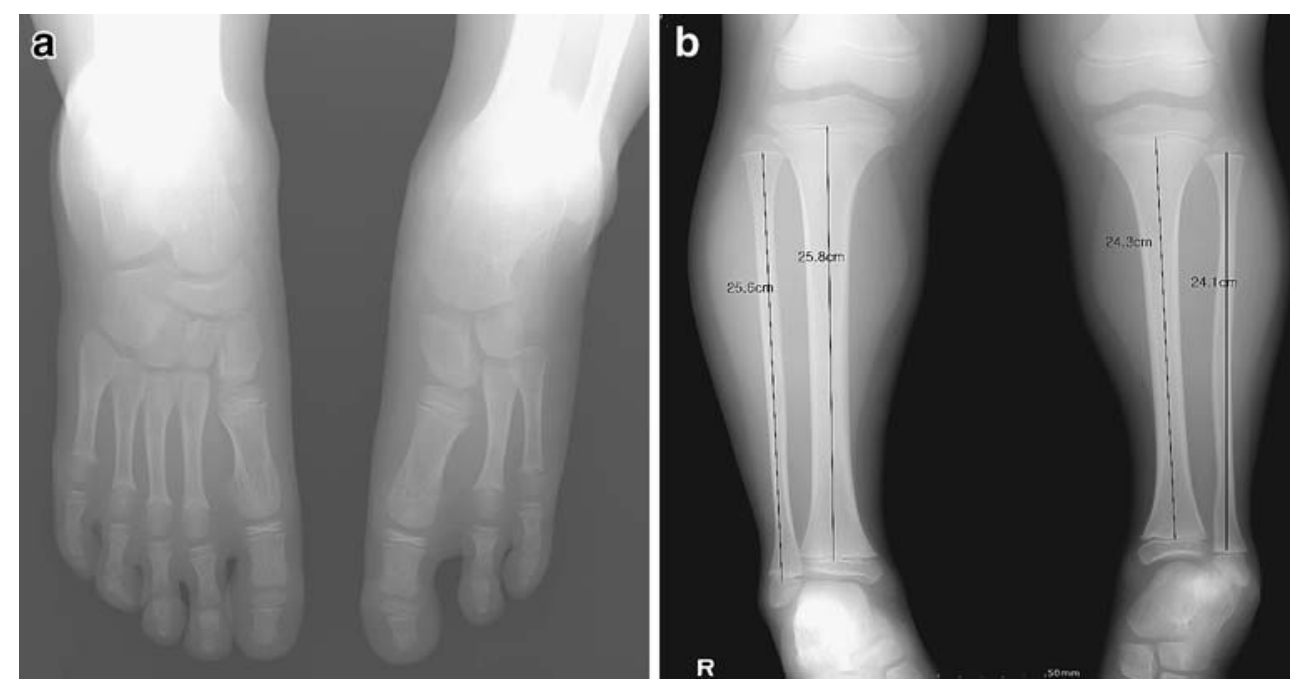

using the multiplier method. We compared the limb length discrepancies between the terminal hemimelic group and fibular hemimelic group. Also we examined the severity of lateral ray absence (three-ray foot vs four-ray foot) to determine whether there was any influence on the limb length discrepancies.

Knee valgus was evaluated using knee radiographs and was calculated using the condylar height ratio, which was calculated by dividing the perpendicular height of the lateral epiphysis by that of the medial epiphysis [3]. We considered a condylar height ratio of less than 0.75 as a evidence of knee valgus. Knee instability was evaluated using physical examinations, such as, the Lachman, varus, and valgus tests. In cruciate-deficient knees, the radiographic evidence consisted of flattening of the tibial eminence. Tibial bowing and ball and socket ankle joints were evaluated using lower leg and ankle radiographs. Ankle instability was evaluated with valgus and varus stress view. We considered an ankle as being unstable, if talar tilt was more than eight degrees greater than that of the normal side. Tarsal coalition and clubfoot were evaluated using standard anterior-posterior, lateral and oblique foot radiographs.

The fibular hemimelic and terminal hemimelic groups were compared with respect to the above measured parameters. The Mann-Whitney test (SPSS software; SPSS Inc., Chicago, IL) was used for the statistical analysis.

\section{Results}

\section{Clinical features}

\section{Leg length discrepancy}

Affected limbs showed lower limb shortening. The mean expected length discrepancy of lower legs at maturity was
$26.5 \mathrm{~mm}$ (range, 19.8-31.9) in the terminal hemimelic group, and $48.7 \mathrm{~mm}$ (range, 34.3-63.2) in fibular hemimelic group, which was significantly different in the two groups $(p=0.003)$. The mean expected length discrepancy of lower legs at maturity was $30.0 \mathrm{~mm}$ (range, 27.0-34.3) in the three-ray foot patient, and $42.6 \mathrm{~mm}$ (range, 19.863.2) in the four-ray foot patient, which was not significantly different in the two groups ( $p=0.273$ ).

\section{Knee}

Mean condylar height ratio in the terminal hemimelic group was 0.84 (range, 0.82-0.86), but in the fibular hemimelic group was 0.71 (range, 0.63-0.78), which was significantly different ( $p=0.003$ ) (Fig. 2). Applying the condylar height ratio of 0.75 as a criterion of knee valgus, none had knee valgus in the terminal hemimelic group but five of seven limbs had knee valgus in the fibular hemimelic group. Two patients in the fibular hemimelic group had knee instability and tibial spine hypoplasia.

\section{Lower leg}

Two patients had tibial bowing of more than seven degrees versus the controlateral side in fibular hemimelic group.

\section{Foot and ankle}

Ball-and-socket deformity of the ankle was present in all patients in both groups and tarsal ossification center appearances were delayed. Tarsal coalition was detected in four patients in each group. Ankles were stable in terminal hemimelic group, but relatively unstable according to the varus stress test in three of seven patients in the fibular hemimelic group. 
Fig. 2 Fibular hemiemlia patient shows knee valgus deformity. However, terminal hemimelia of the lower extremity patient don't have any knee deformity. a. Fibular hemiemlia patient. b. Terminal hemimelia of the lower extremity patient
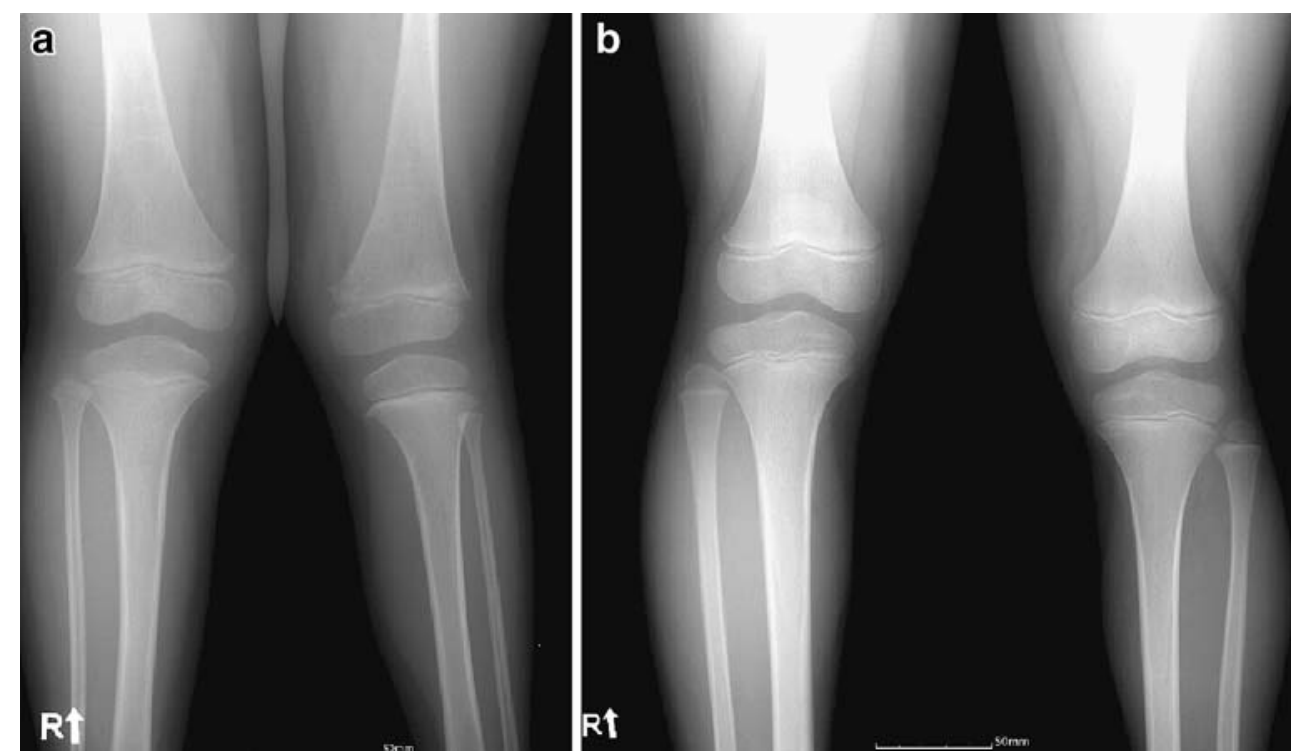

\section{Management}

In terminal hemimelic group, no patients needed surgical treatment prior to the final evaluation. However, in the fibular hemimelic group four of seven patients underwent surgical treatment. In one patient, epiphysiodesis of the distal femur and proximal tibia was performed at age 12 years 3 months for leg length inequality. In the second patient, tibial lengthening using Ilizarov apparatus for leg length inequality and medial cuneiform open wedge osteotomy for varus deformity of foot were performed at age 10 years 11 months. In the third patient, tibial and femoral lengthening was conducted using the Ilizarov apparatus at 11 years of age. Concomitantly, deformity correction of knee valgus was performed at the femoral osteotomy site. In the forth patient, tibial lengthening was performed using Ilizarov apparatus at 12 years of age, and medial tibial stapling for knee valgus was performed at one and half year after tibial lengthening.

\section{Discussion}

Achterman and Kalamchi [1] classified the congenital deficiencies of the fibular according to the severity of fibular hypoplasia. In type IA, the proximal fibular epiphysis is distal to the level of the tibial growth plate, whereas the distal fibular growth plate is proximal to the dome of the talus. In type IB, there is a partial absence of the fibula and proximally the fibula is absent for 30 to 50 percent of its length, whereas distally it is present but unable to support the ankle. Type II includes all limbs when there is a complete absence of the fibula or when only a distal, vestigial fragment is present. Fibular hypoplasia represents a substantial portion of fibular hemimelia cases using this classification. Moreover, Achterman and Kalamchi pointed out that as hypoplasia of the fibula becomes more severe, so the clinical manifestations become more marked and treatment more radical. Thus, we excluded the fibular hemimelia type IB \& II, which presented severe deformities in our series. Type IA which is the mildest form of the fibular hemimelia was considered suitable to clearly show the common and different features of the terminal hemimelia of the lower extremity and fibular hemimelia.

Terminal hemimelia overlaps with fibular hemimelia in terms of clinical features below the ankle joint such as, the ball and socket ankle joint and tarsal coalition. However, terminal hemimela was found to be milder than fibular hemimelia in terms of femoral and tibial limb shortening. Moreover, clinical features above the ankle joint were also different in terminal hemimelia, namely, knee valgus, knee instability, and tibial bowing were not identified (Table 2).

Searle CP et al. [9] proposed type 0 fibular hemimelia which had features of fibular hemimelia syndrome except

Table 2 Comparative data for the terminal hemimelic and fibular hemimelic group

\begin{tabular}{lll}
\hline & $\begin{array}{l}\text { Terminal } \\
\text { hemimelic group }\end{array}$ & $\begin{array}{l}\text { Fibular } \\
\text { hemimelic group }\end{array}$ \\
\hline Leg length discrepancy & mild & Severe \\
Knee valgus & - & + \\
Knee instability & - & + \\
Tibia bowing & - & + \\
Ankle instability & - & + \\
Ankle morphology & $\mathrm{B} \& \mathrm{~S}^{*}$ & $\mathrm{~B} \& \mathrm{~S}$ \\
Tarsal coalition & + & + \\
\hline
\end{tabular}

*B\&S; ball and socket ankle joint 
for radiographically normal fibulae. They considered this a mild type of fibular hemimelia with clinical features commonly presented in fibular hemimelia, but without fibular hypoplsia. They evaluated the following features of fibular hemimelia syndrome; limb shortening, absent lateral rays, ball and socket ankle joint, tarsal coalition, knee valgus, tibial spine hypoplasia, cruciate instability and clubfoot in a total of eight features and they considered a fibular hemimelic syndrome to be present if a patient had two or more features described above. In their series, limb shortening and lateral ray deficiency were the most common features. Thirteen of their 16 cases had an absent lateral ray and the others had a ball and socket ankle joint and tarsal coalition. Thus, we believe that the type 0 fibular hemimelia and terminal hemimelia of the lower extremity were actually same entity, however, different expression.

Stevens and Arms [10] questioned the term of fibular hemimelia. They believed that this term understates the spectrum of anomalies that may be associated and the broader term, postaxial hypoplasia, afforded a better description. We believe that the terminal hemimelia of the lower extremity and fibular hemimelia could be viewed as subsets of postaxial hypoplsia. Postaxial hypoplasia is caused by perturbation of the zone of polarizing activity (ZPA) $[2,6,8]$. ZPA has a key role in postaxial limb development. Sonic hedgehog (Shh) is expressed in the ZPA and appears to mediate the action of the ZPA. Moreover, complete loss of Shh throughout the embryo by conventional gene knockout strategy leads to loss of posterior skeletal structure in the zeugopod and autopod (below the knee joint) [5]. We believe that distinction between the terminal hemimelia and fibular hemimelia depends on the time of initiation of Shh expression perturbation. In terminal hemimelia, abnormalities were restricted below the ankle joint. Thus, we can assume with security that a reduction in Shh expression probably occurs during the late phase of the limb bud development, during which Hoxd-12 and Hoxd-13 are collinearly expressed [7]. Limb shortening is a uniform finding of postaxial hypoplasia. Outgrowth in the proximal-distal dimension primarily depends on fibroblast growth factor (Fgf) signalling from the apical ectodermal ridge (AER). Shh signaling is essential for maintaining Fgf expression overlying AER [11]. Thus, Shh expressional perturbation reduces Fgf expression and retards proximal-distal limb bud outgrowth. The reason why limb shortening in terminal hemimelia is milder than that of fibular hemimelia can be explained as a later onset of Shh expressional pertubation terminal hemimelia.

In this study, no terminal hemimelia patient underwent surgical treatment and knee valgus and knee instability were not observed in these patients. Moreover, no patient complained of foot pain or gait disturbance. However, further evaluations are necessary because late onset foot pain may develop due to tarsal coalition. At the final evaluation, leg length discrepancies averaged 16.6 (range, 13-19) $\mathrm{mm}$ in terminal hemimelic group, which could be accommodated by shoe modification. Expected leg length discrepancy at maturity in this group was 26.5 (range, 19.8-31.9) $\mathrm{mm}$. Thus, a leg length equalising procedure would be necessary in some patients, but we believe that this is the only surgical procedure likely to be necessary in cases of terminal hemimelia of the lower extremity.

\section{References}

1. Achterman C, Kalamchi (1979) Congenital deficiency of the fibular. J Bone Joint Surg Br 61(2):133-157

2. Bell SM, Schreiner CM, Goetz JA, Robbins DJ, Scott WJ Jr (2005) Shh signaling in the limb bud ectoderm: potential role in teratogen-induced postaxial ectrodactyly. Dev Dyn 233:313-325

3. Boakes JL, Stevens PM, Moseley RF (1991) Treatment of genu valgus deformity in congenital absence of the fibula. J Pediatr Orthop 11:721-724

4. Bohne WH, Root L (1977) Hypoplasia of the fibula. Clin Orthop 125:107-112

5. Chiang C, Litingtung Y, Harris MP, Simandl K, Li Y, Beachy PA, Fallon JF (2001) Manifestation of the limb prepattern: Limb development in the absence of sonic hedgehog function. Dev Biol 236:421-435

6. Kraus P, Fraidenraich D, Loomis CA (2001) Some distal limb structures develop in mice lacking sonic hedgehog signaling. Mech Dev 100:45-58

7. Nelson CE, Morgan BA, Burke AC, Laufer E, DiMambro E, Murtaugh LC, Gonzales E, Tessarollo L, Parada LF, Tabin C (1996) Analysis of Hox gene expression in the chick limb bud. Development 122:1449-1466

8. Ros MA, Dahn RD, Fernandez-Teran M, Rashka K, Caruccio NC, Hasso SM, Bitgood JJ, Lancman JJ, Fallon JF (2003) The chick oligozeugodactyly(ozd) mutant lacks sonic hedgehog function in the limb. Development 130:527-537

9. Searle CP, Hildebrand RK, Lester EL, Caskey PM (2004) Findings of fibular hemimelia syndrome with radiographically normal fibulae. J Pediatr Orthop B 13(3):184-188

10. Stevens PM, Arms D (2000) Postaxial hypoplasia of the lower extremity. J Pediatr Orthop 20(2):166-172

11. Zuniga A, Haramis AP, McMahon AP, Zeller R (1999) Signal relay by BMP antagonism controls the SHH/FGF4 feedback loop in vertebrate limb bud. Nature 401:598-602 